\title{
COMPORTAMENTO GEOTÉCNICO DE MISTURAS GRANULOMETRICAS DE SOLO-GRITS 1
}

\author{
Carlos Cardoso Machado² e Carla Ribeiro Machado e Portugal ${ }^{3}$
}

\begin{abstract}
RESUMO - Neste artigo, analisou-se a influência das diversas frações granulométricas do resíduo grits nos parâmetros ótimos de compactação, resistência mecânica e expansão, quando em misturas com dois solos típicos da Zona da Mata Norte de Minas Gerais, Brasil, com fins de aplicação em estradas florestais. Os teores de resíduo empregados nas misturas foram de 4, 8, 12,16, 20, 24 e 28\%, em relação à massa seca de solos, trabalhando-se com as energias de compactação dos ensaios Proctor intermediário e modificado. As frações de resíduo estudadas foram as equivalentes a argila e silte $(\varnothing \leq 0,074 \mathrm{~mm})$, areia $(0,074 \mathrm{~mm} \leq \varnothing \leq 2,0 \mathrm{~mm})$ e pedregulho $(2,0 \mathrm{~mm} \leq \varnothing \leq 76 \mathrm{~mm})$, considerando-se a escala granulométrica adotada pelo DNIT (1996). Fez-se uso do ensaio de CBR para avaliação da capacidade de suporte e expansão dos solos e misturas. Os resultados indicaram que a fração fina do grits é a que mais contribui para ganhos de resistência mecânica, o que evidencia a sua importância na reatividade das misturas, sendo a fração pedregulho a menos influente no ganho de capacidade de suporte dos solos.
\end{abstract}

Palavras-chave: Estabilização de solos, Resíduo industrial grits, Granulometria, Reatividade solo-grits e Estradas florestais.

\section{MECHANICAL BEHAVIOR OF THE GRANULOMETRICS MIXTURES OF SOIL-GRITS}

\begin{abstract}
The objective of this experiment was to analyze the influence of size distribution of the industrial waste, named grits, on the optimum compaction parameters, mechanical strength and expansion of two typical soils in the North Forest Zone of Minas Gerais State, Brazil, for forest road applications. Contents of waste used in the mixtures were 4, 8, 12, 16, 20, 24 and $28 \%$ regarding soils dry mass, working with compacting units of intermediary and modified Proctor trials. The assessed waste fractions were those equivalent to clay and silt $(\varnothing \leq 0.074 \mathrm{~mm})$, sand $(0.074<\varnothing \leq 2 \mathrm{~mm})$, and gravel $(2 \mathrm{~mm}<\varnothing \leq 76 \mathrm{~mm})$, considering the size scale adopted by DNIT (DNIT, 1996). Bearing capacity and expansion of soils and mixtures were evaluated by using the CBR test. Results showed that the fine fraction of the grits is the one which contributes the most for gains in the mechanical strength, evidencing its importance in the reactivity of the mixtures, and gravel is that influences the least the gain of bearing capacity of the soils.
\end{abstract}

Keywords: Soil stabilization, Industrial grits waste, Grain size distribution and Soil-grits reactivity. Forest roads.

\section{INTRODUÇÃOO}

Na estabilização química de solos para fins rodoviários, determinado aditivo é incorporado a um solo, cuja mistura é compactada posteriormente segundo determinados critérios técnicos, alcançando-se, assim, características desejáveis de resistência mecânica e durabilidade. Os mecanismos envolvidos nesse processo podem ser os mais diversos possíveis. Segundo Lambe e Michaels (1954), os estabilizantes químicos quando adicionados aos solos podem atuar como agentes impermeabilizantes, dispersantes ou agregantes que atuam modificando as suas propriedades físicas e, ou, químicas.

Com relação ao processo de estabilização, o conhecimento das frações granulométricas constitutivas

\footnotetext{
${ }^{1}$ Recebido em 15.12.2011 e aceito para publicação em 19.04.2012.

2 Universidade Federal de Viçosa, UFV, Brasil. E-mail: <carloscardosomachado@ terra.com.br>.

${ }^{3}$ C \& R Agroambiental Ltda. E-mail: <carlamacport@ hotmail.com>.
} 
das amostras de solo e do material estabilizante, bem como a caracterização química deste último, é fator essencial para o reconhecimento de um aditivo como agente de estabilização eficaz. Considerando esse aspecto, este artigo teve por finalidade analisar a influência da granulometria do resíduo industrial grits na resistência mecânica de misturas solo-grits compactadas, com base nos seus valores CBR e expansão.

\section{MATERIAL E MÉTODO}

\subsection{Solos e grits}

Trabalhou-se com dois solos da microrregião de Viçosa, Zona da Mata Norte de Minas Gerais, aqui denominados Solos 1 e 2 . O solo 1 é um material laterítico argiloso, classificado como LG' pela Metodologia MCT (NOGAMI e VILLIBOR, 1995); o solo 2 é um material não laterítico arenoso, pertencente ao grupo NS' da mesma classificação.

O estabilizante químico dos solos ensaiados é o resíduo industrial denominado grits, que é gerado durante o processo de extração de celulose nas empresas que utilizam o processo Kraft. Ele é um material sólido, acinzentado, de granulometria ampla que engloba as frações pedregulho, areia, silte e argila, sendo classificado como classe II (ABNT, 1987), ou seja, material não inerte. O que despertou o interesse deste estudo foi o fato de o grits se tratar de um resíduo constituído de mistura de material, com destaque para a cal.

\subsection{Traços e processamentos do grits}

a) Fase 1 - Utilizaram-se duas amostras distintas de grits, para fins de identificação de sua granulometria e possíveis faixas de variação.

b) Fase 2 - Executaram-se misturas envolvendo os solos 1 e 2 e grits, empregando sete teores crescentes de resíduo calculados em relação às massas secas dos solos, os quais foram: 4, 8, 12, 16, 20, 24 e $28 \%$. Os teores de umidade empregados foram os equivalentes às umidades ótimas e corpos-de-prova dos solos compactados na energia do ensaio Proctor normal. Após a mistura, as amostras solos-grits foram passadas na peneira de abertura nominal de 2,0 mm (n⿳o 10), umedecidas na umidade ótima e deixadas curar em câmara úmida, em sacos plásticos hermeticamente fechados por um período de sete dias. Após a cura, as amostras foram secas ao ar, obtendo-se as frações a serem empregadas nos ensaios de granulometria das misturas solo-grits. c) Fase 3 - Determinou-se a capacidade de suporte das misturas via ensaio CBR, trabalhando com corposde-prova moldados com teores de resíduo de 4, 8, 12, $16,20,24$ e $28 \%$ em relação às massas de solos secos. Nessas misturas, empregou-se o resíduo sob duas formas: (a) sem processamento, ou seja, da forma como foi fornecido pela empresa; e (b) após sua passagem na peneira de abertura nominal de 2,0 mm ( $\mathrm{n}^{\circ} \mathrm{10}$ ), separando-se, assim, a fração equivalente ao pedregulho, que foi descartada, e usando-se as frações areia, silte e argila. Para os fins deste trabalho, esse processo denominou-se processamento do grits.

d) Fase 4 - Empregaram-se os traços de 8, 16 e $24 \%$ de grits nas misturas; passou-se o resíduo nas peneiras de aberturas nominais de $2,0 \mathrm{~mm}$ (no 10$)$ e $0,074 \mathrm{~mm}$ (no 200). A fração do resíduo que passou na peneira de $\mathrm{n}^{\circ} 10$ e ficou retida na peneira de $\mathrm{n}$ - 200 , o que equivale à areia, foi empregada nos ensaios, bem como a fração que passou na peneira de $\mathrm{n}^{\circ} \mathbf{2 0 0}$, equivalente a silte e argila, que foram usados nos ensaios CBR nas composições apresentadas na Tabela 1 .

\subsection{Ensaios realizados}

Para conhecer a contribuição das diferentes frações constitutivas do resíduo na estabilização das misturas solo-grits, procedeu-se à execução dos seguintes ensaios: (i) Fase 1 - Realização de ensaios de granulometria conjunta com amostras de grits: (DNIT, 1996) - ME 051; (ii) Fase 2 - Ensaios de granulometria conjunta com as misturas solo-grits: (DNIT, 1996) - ME 051; (iii) Fase 3 - Ensaios de $\mathrm{CBR}_{5 \text { pontos }}$ : com as misturas solo-grits (DNIT, 1994) - ME 049, para avaliação do comportamento dos parâmetros ótimos de compactação, resistência mecânica e expansão das misturas solo-grits, fazendo-se uso das energias de compactação referentes aos ensaios Proctor intermediário e Proctor modificado, não se realizando períodos de cura nos corpos-de-prova; e

Tabela 1 - Composições granulométricas do grits. Table 1 - Composition of Grits grain size.

\begin{tabular}{lcc}
\hline Composição & \multicolumn{2}{c}{ \% Resíduo Grits } \\
\cline { 2 - 3 } & $\begin{array}{c}\text { Entre a \# 2,0 mm } \\
\text { a \# } 0,074 \mathrm{~mm}\end{array}$ & $\begin{array}{c}\text { Processado } \\
\text { \# } 0,074 \mathrm{~mm}\end{array}$ \\
\hline I & 100 & 0 \\
$I I$ & 87,5 & 12,5 \\
$I I I$ & 75 & 25 \\
$I V$ & 50 & 50 \\
$V$ & 0 & 100 \\
\hline
\end{tabular}


(iv) Fase 4-Ensaios de $\mathrm{CBR}_{1 \text { ponto }}$ : (DNIT, 1994) - ME 049, para avaliação da reatividade da fração fina do resíduo grits nas misturas solos-grits compactadas na energia do Proctor intermediário e curadas por 28 dias em câmara úmida, objetivando permitir possíveis ocorrências de reações químicas, em especial reações pozolânicas.

\section{RESULTADOS E DISCUSSÃO}

\subsection{Granulometria do grits e das misturas solo-grits}

A Figura 1 mostra a curva granulométrica do grits; em seu item (a), observa-se o pouco efeito dispersante proporcionado na sedimentação das partículas pelo hidróxido de sódio e pelo hexametafosfato de sódio. Esse fato pode ser explicado, em primeiro lugar, pelos quantitativos de defloculantes empregados, visto que são específicos para dispersão de partículas argilosas de solos; outro fato a relatar é a presença relativamente elevada de sódio $(0,70 \%)$ já presente no resíduo, que o torna por si só altamente dispersivo.

Ainda pela Figura 1b, nota-se que o resíduo grits possui granulometria diversificada, com predominância de tamanho de partículas referentes à fração areia, cerca de 70\%, em média. Esse material possui também: (i) frações mais grosseiras, representadas por cerca de $10 \%$ ou mais equivalentes a pedregulho, constituídas por materiais cristalizados de difícil quebra, originados
(,) provavelmente em processos de resfriamento durante a sua geração na indústria; e (ii) frações menores (silte: $15-25 \%$ e argila: $<5 \%$ ).

O grits se assemelha, pela sua granulometria e características de plasticidade (NP), a um material classificado pelo sistema rodoviário americano TRB como A-2-4 (0), referente a uma areia siltosa; entretanto, seu uso em camadas constitutivas de pavimentos rodoviários em substituição a solos locais não parece recomendável, seja ou por falta de ligação química entre as suas partículas ou pelos possíveis riscos ambientais passíveis de ocorrência devido à sua introdução em ecossistemas florestais. Contudo, o seu emprego como estabilizante químico respalda-se no fato de que na sua constituição há a presença de óxido de cálcio. A curva granulométrica do grits é apresentada na Figura 1.

Mudanças na granulometria dos solos 1 e 2 em decorrência da incorporação de grits às suas massas podem ser analisadas na Figura 2. Na granulometria do solo 1, notou-se a presença de partículas maiores, principalmente as equivalentes à fração areia; o aumento do teor de grits proporcionou diminuição da fração argila de $70 \%$ para cerca de $50 \%$. Entretanto, o comportamento textural do solo 1 , ou seja, de material argiloarenoso-siltoso, não foi alterado, ficando evidenciado que o período de cura de sete dias a que foram submetidas as misturas não fez que ocorresse

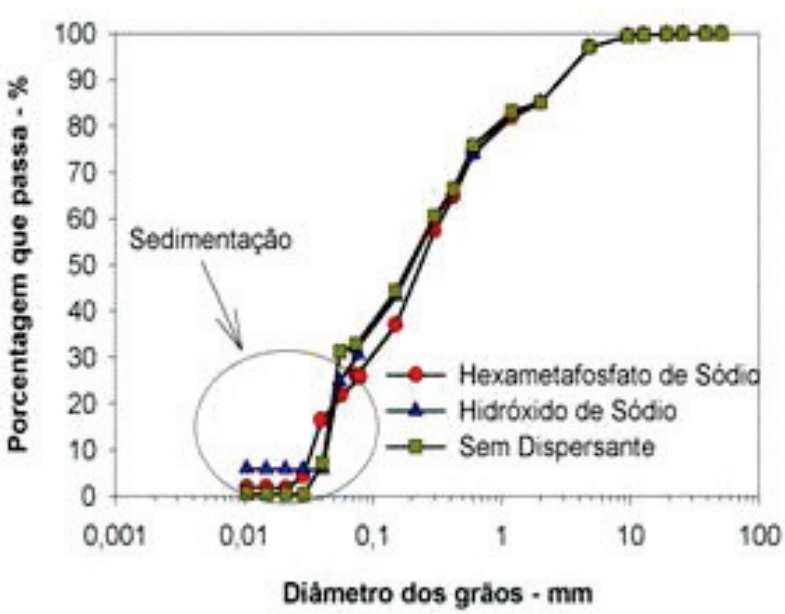

a) Açào dos Dipersantes

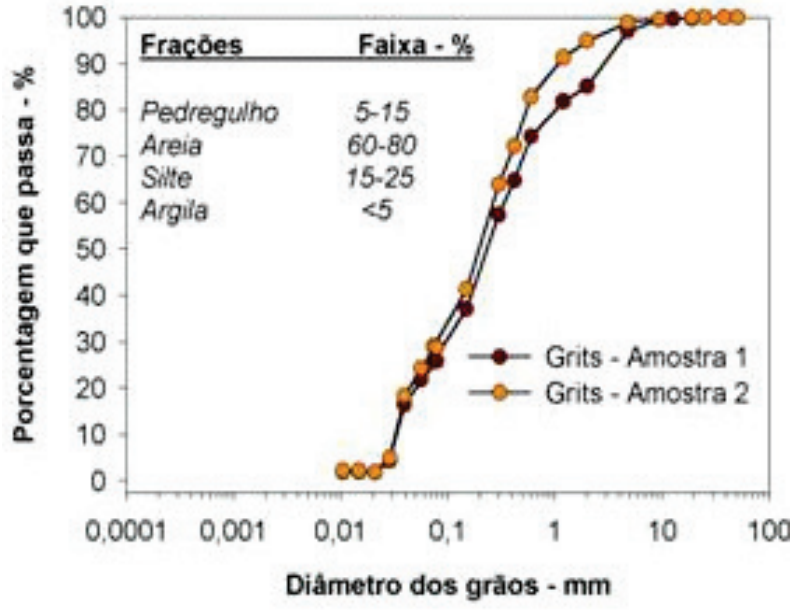

b) Granulometria de amostras de Grits

Figura 1 - Análise granulométrica do grits.

Figure 1 - Analyses of Grits grain.

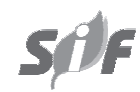

Revista Árvore, Viçosa-MG, v.36, n.3, p.519-526, 2012 


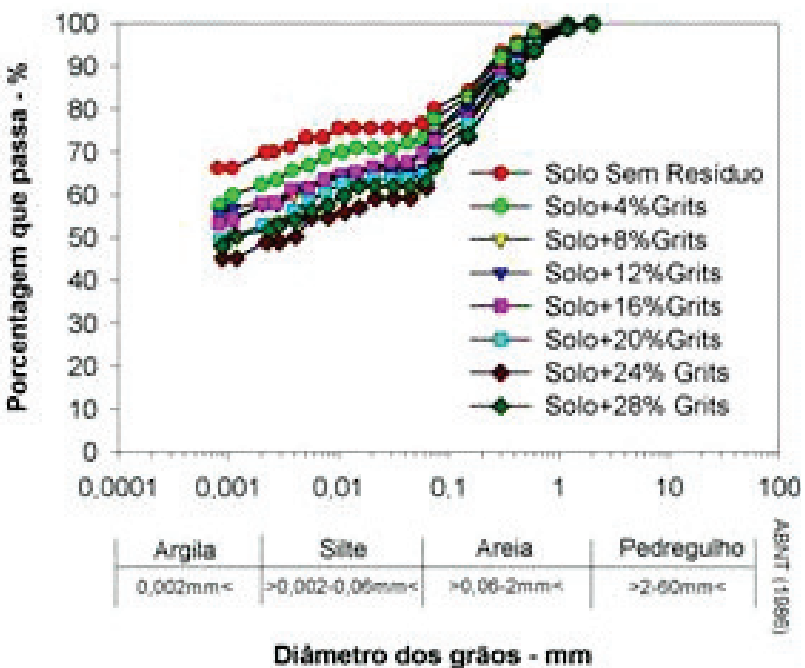

a) Misturas Solo1-Grits

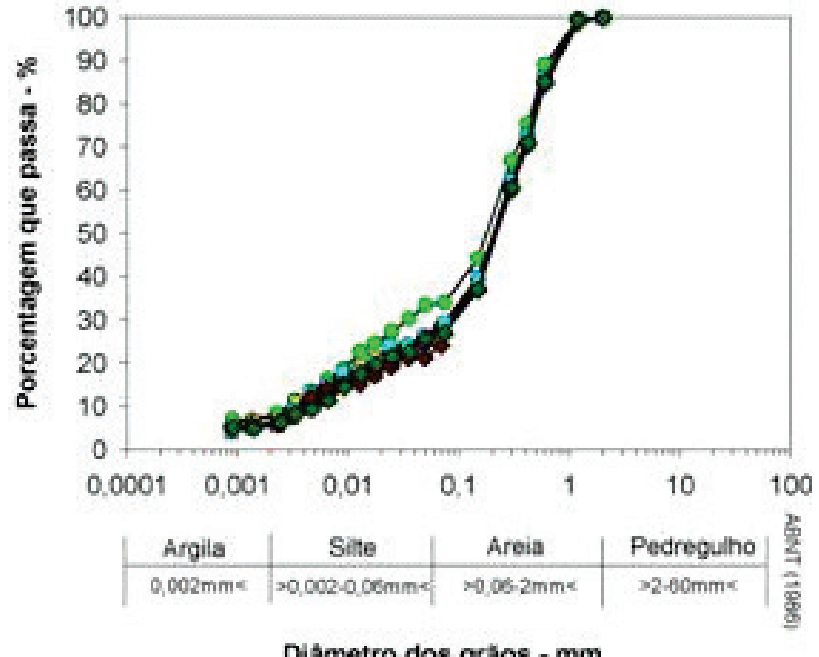

Diâmetro dos grăos - mm

b) Misturas Solo2-Grits

Figura 2 - Curvas granulométricas das misturas solo-grits. Figure 2-Granulometrics curves of the soil-grits mixtures.

aglomeração ou floculação das partículas argila desse solo, formando grumos maiores, o qual atuou apenas como alterador físico da granulometria.

As misturas solo 2-grits tiveram o mesmo comportamento granulométrico do solo sem adição de resíduo, qual seja, de material texturalmente arenoargilo-siltoso evidenciando a não formação de particulados maiores; a granulometria do solo 2 e a do resíduo se aproximam em muito; e a fração argila, responsável pelos fenômenos físico-químicos que ocorrem na superfície dos argilominerais, não é tão expressiva nesse solo.

\subsection{Influência da fração grosseira do grits na capacidade de suporte e expansão das misturas solos- grits compactadas}

Analisando as curvas de compactação em duas energias (Intermediária e Modificada) da Figura 3 e tomando os parâmetros ótimos de compactação, $\mathrm{W}_{\text {ót. }}$ e $g_{\text {dmáx. }}$, nota-se que os valores de CBR das misturas solo 1-grits foram inferiores aos do solo 1 (forma natural) e inversamente proporcionais ao aumento no teor de resíduo. Essas misturas praticamente não se alteraram em decorrência do processamento do resíduo na peneira de abertura nominal de 2,0 $\mathrm{mm}$, mesmo quando compactadas na energia modificada; nesse mesmo enfoque, os valores de pesos específicos secos máximos foram ligeiramente inferiores nas misturas com a fração do resíduo passado na peneira de $2,0 \mathrm{~mm}$, considerando-se a compactação das misturas solo 1-grits na energia intermediária. Na energia modificada, os parâmetros ótimos de compactação não sofreram alterações significativas em expansão, com pequenas discrepâncias dos teores de 20, 24 e $28 \%$ de grits.

Analisando a Figura 4, pode-se observar que as misturas solo 2-grits tiveram o seguinte comportamento, quanto ao aspecto compactação: (i) pequeno aumento na umidade ótima nas misturas compactadas na energia intermediária, atingindo-se maiores valores nas misturas contendo o resíduo processado; (ii) na energia modificada, os teores ótimos de umidade praticamente não se alteraram; e (iii) os valores de $g_{\text {dmáx. }}$ foram ligeiramente superiores no resíduo processado na peneira de 2,0 $\mathrm{mm}$ das misturas compactadas na energia intermediária, notando-se comportamento diferenciado quando da compactação realizada na energia modificada, ou seja, maiores valores de $\mathrm{g}_{\text {dmáx. }}$ nas misturas contendo o resíduo na sua forma pura, sem processamento.

Os valores de resistência mecânica e expansão foram medidos via ensaio CBR (Figura 5). As misturas solo 1-grits, quando compactadas na energia 


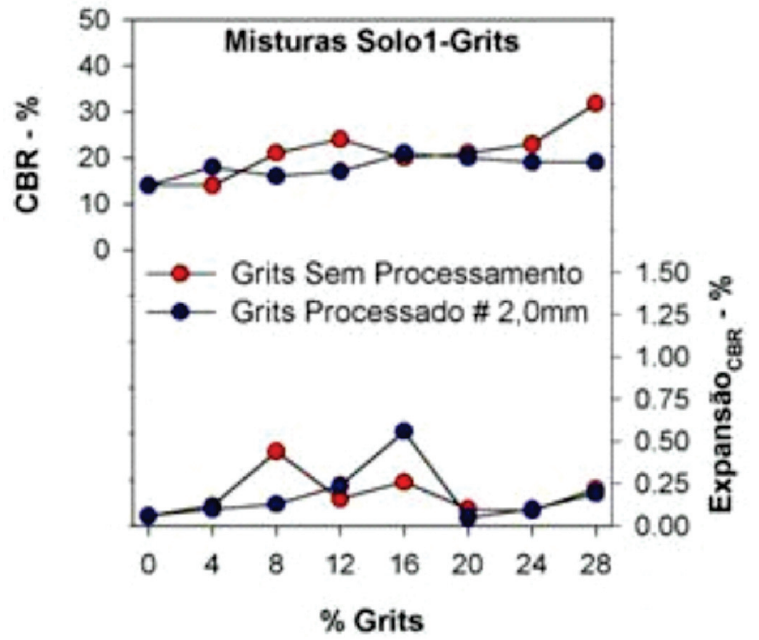

a) Compactação na En. Intermediária

Figura 3 - Curvas de compactação com duas energias. Figure 3 - Compactation curves with two energy.

intermediária, apresentaram pouca variação nos seus valores CBR, em função do processamento do grits, sendo notada maior discrepância no teor de $28 \%$, em que ocorreu queda de aproximadamente $40 \%$ na resistência, quando se empregou a fração de resíduo que passou na \# 2,0 $\mathrm{mm}$. Comportamento distinto foi notado nas misturas solo 1-grits compactadas na energia modificada, em que os resultados CBR, com o uso do resíduo processado, foram, em todos os tratamentos, superiores aos das misturas com o grits puro, sendo observadas discrepâncias significativas na capacidade de suporte da maioria dos tratamentos. Uma razão para esse fato pode ser a tendência a maiores valores de densidade, principalmente nos teores superiores a $20 \%$ de resíduo, obtidos nessa energia e nas misturas solo 1-grits, utilizando o resíduo processado. Com relação aos valores de expansão, notou-se nas misturas solo 1-grits que praticamente eles não se alteraram em função do processamento do resíduo, em ambas as energias de compactação; ressalva seja feita às misturas com 8 e $16 \%$ de grits, compactadas na energia intermediária.

Nas misturas solo 2-grits, notou-se o seguinte comportamento com relação ao índice CBR (Figura 6), em função do processamento do resíduo: (i) quando compactadas na energia intermediária, as misturas praticamente não sofreram alteração na sua resistência,

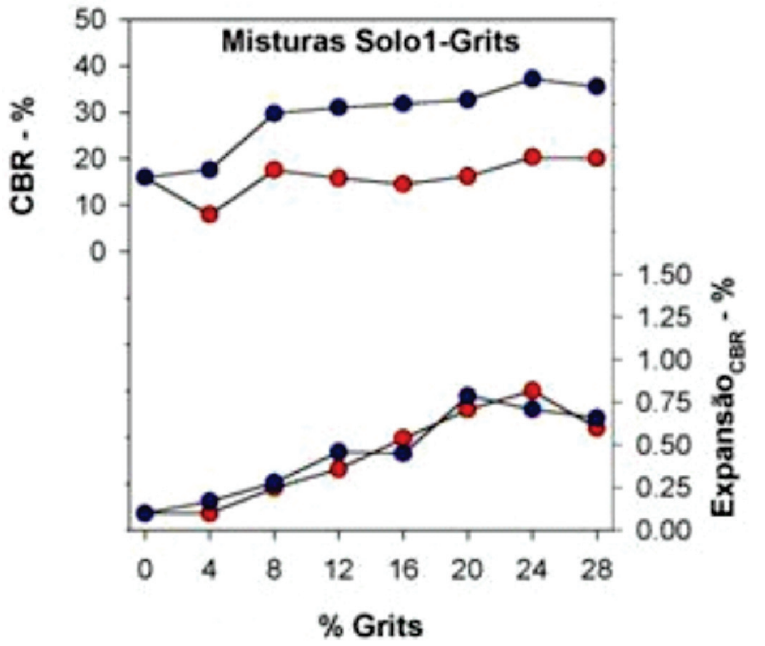

b) Compactação na En. Modificada devido ao processamento do grits na \# 2,0 mm, sendo observada maior discrepância no teor de $28 \%$ de resíduo, em que se obteve valor de CBR de aproximadamente $60 \%$ superior nas misturas com o grits processado; (ii) para compactação na energia modificada houve ligeira tendência a maiores valores de resistência nas misturas com o resíduo processado na peneira de $\mathrm{n}^{\mathrm{o}} 10$. Com relação ao índice de expansão, notaram-se reduções significativas somente nas misturas solo 2-grits compactadas na energia modificada, em que ocorreram quedas em torno de $70 \%$ na expansão quando se empregaram misturas com o resíduo processado.

\subsection{Reatividade da fração fina do grits na resistência e expansão das misturas solo-grits compactadas}

Nessa fase, procurou-se avaliar a reatividade da fração com diâmetro menor que $0,074 \mathrm{~mm}$ nas misturas solo-grits compactadas e curadas. Na Figura 6, referente a valores CBR e expansão, é possível notar com relação à resistência que: (i) misturas solo 1-grits - em todos os teores, à medida que aumentou a parcela de resíduo com diâmetro inferior a $0,074 \mathrm{~mm}$, houve, proporcionalmente, aumentos na resistência, sendo notados maiores discrepâncias a partir de $50 \%$ de resíduo processado na peneira de no 200 ; atingiram-se pontos máximos de CBR com o processamento de $100 \%$ do resíduo nessa mesma peneira. No teor de $24 \%$ de resíduo, 


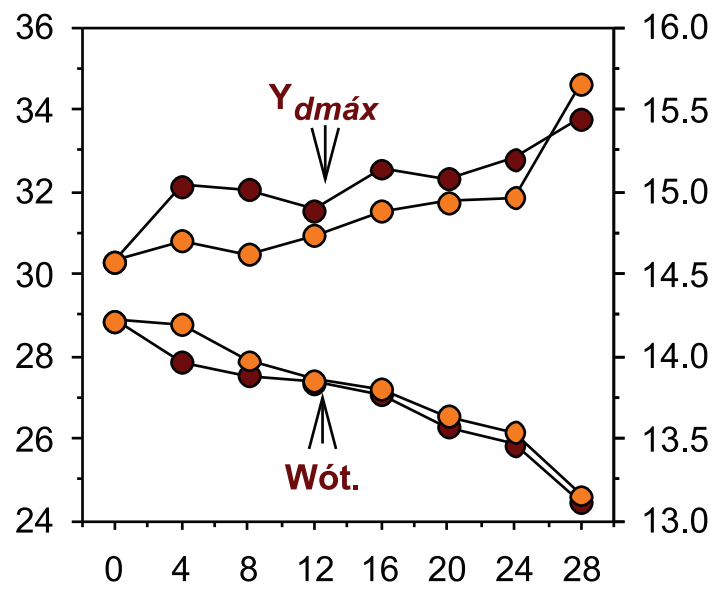

Resíduo Sólido Industrial Grits - \%

a) Misturas Solo1-Grits compactadas na energia intermediária

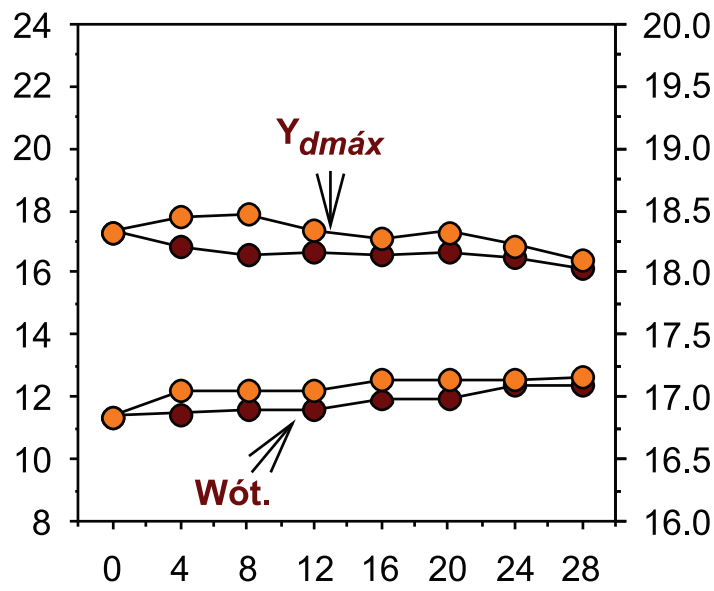

Resíduo Sólido Industrial Grits - \%

c) Misturas Solo2-Grits compactadas na energia intermediária

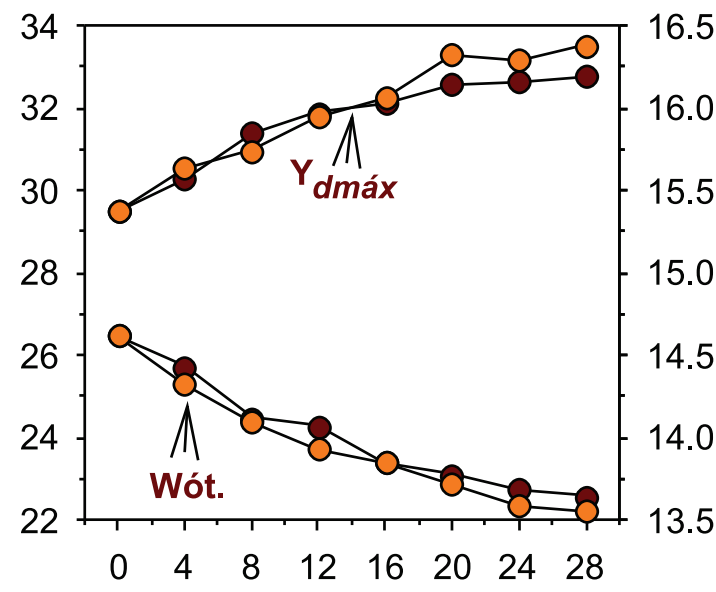

Resíduo Sólido Industrial Grits - \%

b) Misturas Solo1-Grits compactadas na energia modificada

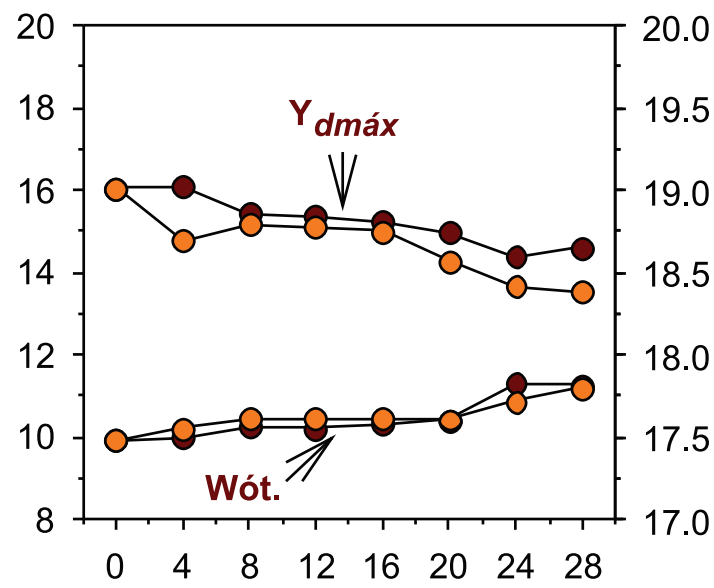

Resíduo Sólido Industrial Grits - \%

d) Misturas Solo2-Grits compactadas na energia modificada

Figura 4 - Reflexos das frações grosseiras do grits na compactação.

Figure 4-Reflexes of the grits gravel fractions in the compacting.

por exemplo, em que os valores de CBR foram maiores, houve ganhos de resistência mecânica de $31 \%$ quando pelo menos $50 \%$ do resíduo foi processado na peneira de abertura nominal de $0,074 \mathrm{~mm}$; e (ii) misturas solo 2-grits - tiveram o mesmo comportamento das misturas solo 1-grits, ou seja, a partir de $50 \%$ de resíduo, com diâmetro inferior a 0,074 mm, empregado nas misturas, ocorreu aumento substancial no CBR, atingindo patamar superior em todos os tratamentos com misturas envolvendo $100 \%$ de resíduo processado na peneira de no 200 . As melhores respostas foram também no traço de $24 \%$ de grits, em que se atingiu valor de CBR superior a $100 \%$, quando se empregou o resíduo com toda a totalidade de sua fração processada na peneira de no 200 . 


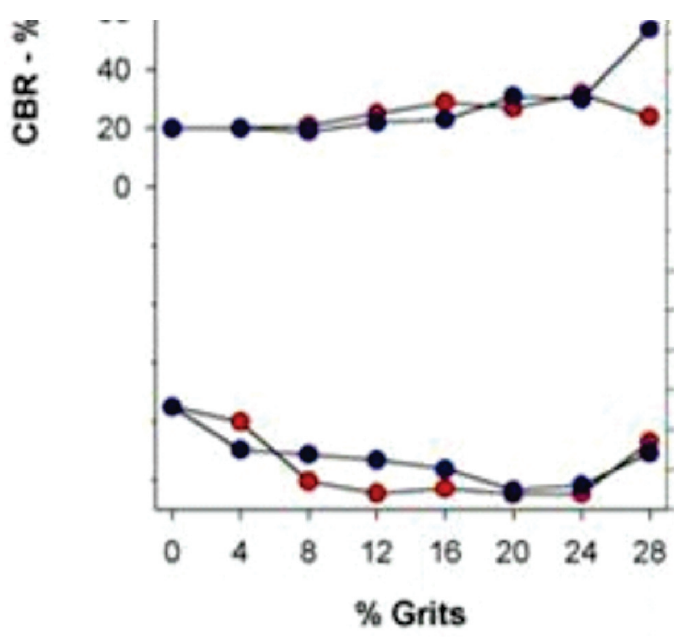

c) Compactaçăo na En. Intermediària

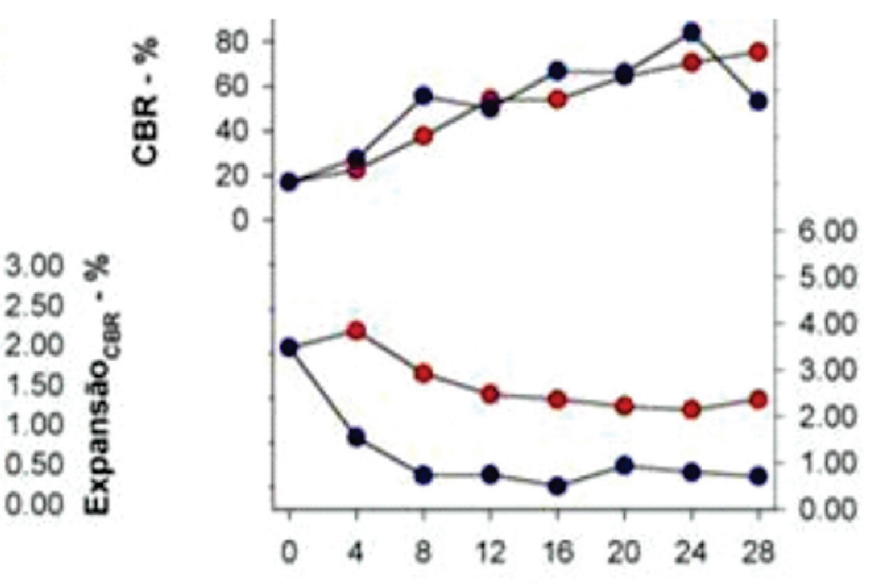

$\%$ Grits

d) Compactaçăo na En.Modificada

Figura 5 - Influência da fração grosseira do grits nos valores de CBR e Expansão.

Figure 5 - Influence of the grits gravel fraction in the CBR and expansion values.

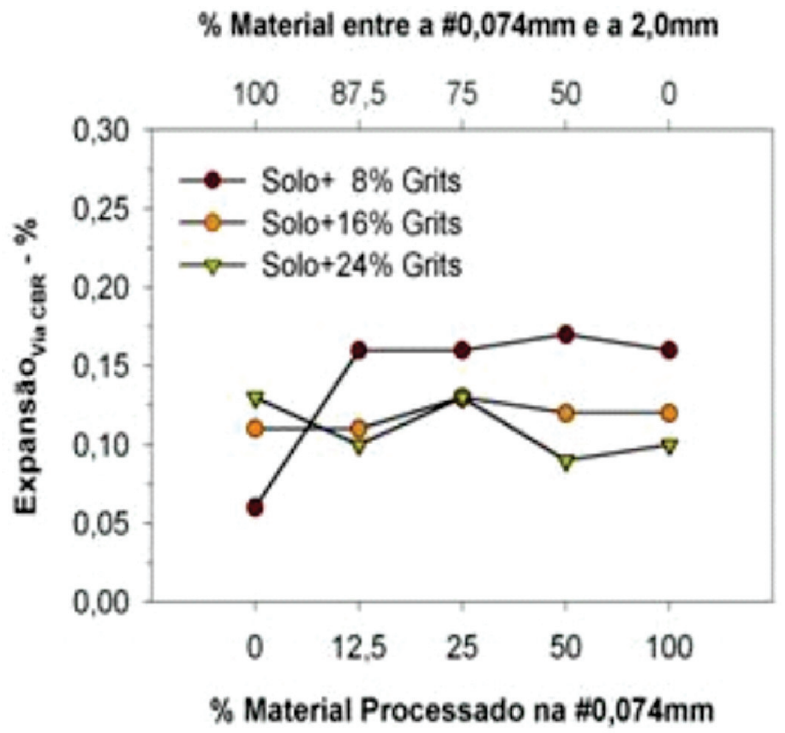

a) Misturas Solo1-Grits

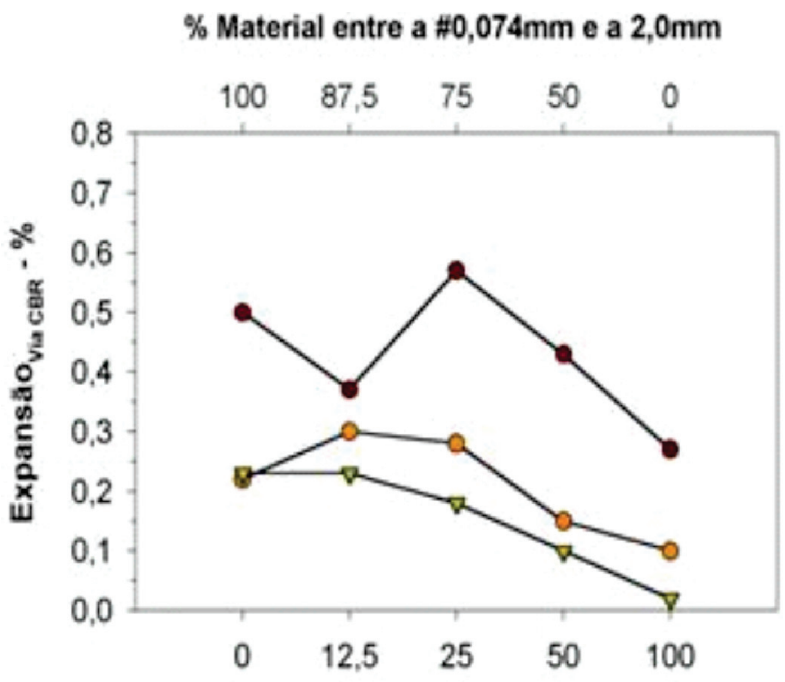

$\%$ Material Processado na $\# 0,074 \mathrm{~mm}$

b) Misturas Solo2-Grits

Figura 6 - Contribuição da fração fina do grits na resistência e na expansão das misturas solo-grits compactadas na energia intermediária e curadas a 28 dias.

Figure 6 - Influence of the grits gravel fraction in the CBR and expansion values at the intermediate compacting energy and 28 days of curing.

Com relação à expansão, as misturas solo 1-grits sofreram pequenas oscilações em decorrência do processamento do resíduo, sendo notada tendência a maiores valores na maioria dos tratamentos, quanto mais fina foi a granulometria do grits. Nas misturas solo 2-grits, notou-se tendência inversa, ou seja, em 
todos os tratamentos, quanto mais fina foi a granulometria do grits, menores foram os valores de expansão. Assim, chegou-se a valores próximos de zero nos teores de 16 e $24 \%$ de grits, considerando este último com $100 \%$ de suas partículas de diâmetro inferior a 0,074 $\mathrm{mm}$ (Figura 6).

\section{CONCLUSÕES}

a) A adição de grits às amostras 1 e 2, nos teores estudados, não proporcionou alteração da textura dos solos, através da possível ocorrência de interações químicas.

b) O par de valores ótimos de compactação das misturas solo-grits praticamente não se alterou pelo processamento do resíduo na peneira de abertura nominal de $2,0 \mathrm{~mm}$.

c) A fração pedregulho $\left(\mathrm{d}^{3} 2,0 \mathrm{~mm}\right)$ pouco contribuiu para os ganhos de resistência mecânica das misturas solo-grits compactadas, sendo notadas nas misturas solo 1-grits, compactadas na energia modificada, as melhores respostas às partículas de grits com $\mathrm{d} £ 2,0 \mathrm{~mm}$.

d) A expansão das misturas solo 2-grits, compactadas na energia modificada, aumentou devido à fração pedregulho do grits, não sendo notada nos demais tratamentos alteração para esse parâmetro. e) As misturas solo-grits tiveram ganhos nos valores CBR proporcionais ao aumento da parcela fina (d $£ 0,074 \mathrm{~mm}$ ) do grits.

f) Os valores máximos de CBR obtidos foram para grits, passando $100 \%$ na peneira de $\mathrm{n}-200$. O aumento da parcela fina levou a incrementos na expansão das misturas solo 1grits e reduções de expansão nas misturas solo 2-grits.

\section{REFERÊNCIAS}

ASSOCIAÇÃO BRASILEIRA DE NORMAS TÉCNICAS - ABNT. NBR 10004: classificação de resíduos sólidos. Rio de Janeiro: 1987. 63p.

DEPARTAMENTO NACIONALDE INFRAESTRUTURA DE TRANSPORTES - DNIT. ME 049: solos: determinação do índice de suporte Califórnia utilizando amostras não trabalhadas. Rio de Janeiro: 1994. 12p.

\section{DEPARTAMENTO NACIONALDE}

INFRAESTRUTURA DE TRANSPORTES - DNIT.

ME 051: solos: análise granulométrica. Rio de Janeiro: 1996. 12p.

LAMBE, T. W.; MICHAELS, A. Altering soil properties with chemicals. Chem. Eng., v.32, n.6, p.488-492, 1954.

NOGAMI, J. S.; VILLIBOR, D. F. Pavimentação de baixo custo com solos lateríticos. São Paulo: Vilibor, 1995. 213p. 